JGG 2022;70:99-104

doi: 10.36150/2499-6564-N357

\title{
Computer-aided cognitive training in patients with neurocognitive vascular impairment: effects on cognition, depression and behavior
}

Sebastiano Vaia ${ }^{1}$, Alessandro lavarone ${ }^{2}$, Franca Moschiano², Carlo Strube ${ }^{1}$, Nadia Gamboz ${ }^{3}$, Giuseppe De Pietro ${ }^{4}$, Sandro Gentile ${ }^{5}$, Elisabetta Garofalo², Maria Sannino ${ }^{2}$, Michele Carpinelli Mazzi ${ }^{2}$

1 "Vaia" Neurodiagnostic Center, Naples, Italy; ${ }^{2}$ Neurology and Stroke Unit, CTO Hospital - AORN Ospedali dei Colli, Naples, Italy; ${ }^{3}$ University of Naples "Suor Orsola Benincasa", Naples, Italy;

${ }^{4}$ National Research Council, Naples, Italy; ${ }^{5}$ University of Campania "Luigi Vanvitelli", Naples, Italy

Received: February 12, 2021

Accepted: December 21, 2021

\section{Correspondence}

Sebastiano Vaia

"Vaia" Neurodiagnostic Center, via E. Tortora 11, 80125 Naples, Italy. E-mail: vaiseb.psy@gmail.com

How to cite this article: Vaia $S$, lavarone $A$, Moschiano $F$, et al. Computeraided cognitive training in patients with neurocognitive vascular impairment: effects on cognition, depression and behavior. Journal of Gerontology and Geriatrics 2022;70:99-104. https://doi. org/10.36150/2499-6564-N357

(C) Copyright by Società Italiana

di Gerontologia e Geriatria (SIGG)

\section{(c) (1) (3) $\odot$}

\section{OPEN ACCESS}

This is an open access article distributed in accordance with the CC-BY-NC-ND (Creative Commons Attribution-NonCommercial-NoDerivatives 4.0 International) license. The article can be used by giving appropriate credit and mentioning the license, but only for non-commercial purposes and only in the original version. For further information: https://creativecommons.org/licenses/by-nc-nd/4.0/deed.en
Aim. The study evaluated the efficacy of computer-aided cognitive training program on cognitive measures, behavioral and depressive symptoms in persons suffering from Major Vascular Neurocognitive Disorder (vNCD).

Methods. Retrospective study on a panel of 55 subjects with vNCD divided into a treatment group (n. 31) and a control group (n. 24) evaluated at baseline (T0) and at endpoint (T1) at 24 weeks. All subjects received the Mini Mental State Examination (MMSE), the Montgomery and Aasberg Depression Rating Scale (MADRS) and the Neuropsychiatric Inventory (NPI-P). The treatment group underwent a 24 weeks of computer-aided cognitive training.

Results. Significant better performances of the treatment group were recorded at T1 on MMSE. A significant reduction of behavioral disorders was shown by the treatment group as compared to the control group. No effect was observed on depression.

Conclusions. Computer aided cognitive training showed positive effects on both behavioral and cognitive dimensions in persons suffering from vNCD.

Key words: nervous system, depression and dementia, behavioral and social sciences

\section{INTRODUCTION}

The growing size of elder population carries with an increased frequency of age-related disorders associated with cognitive impairment and dementia. Among these patients the larger part is given by subjects with Alzheimer's disease (AD), followed by patients suffering from vascular forms of cognitive deterioration, currently labeled as Vascular Cognitive Impairment $(\mathrm{VCl}){ }^{1}$ or, more recently, vascular neurocognitive disorder (vNCD) ${ }^{2}$. Actually, there is a wide evidence of the effectiveness of non-pharmacological treatments in patients with dementia on cognitive ${ }^{3}, \operatorname{mood}^{4}$ and behavioral domains ${ }^{5}$. Cognitive stimulation offers activities for people with dementia who provide benefits in cognition, self reported well being, quality of life, communication and social interaction ${ }^{6}$. Effectiveness of cognitive rehabilitation in 
post-stroke patients was clearly demonstrated in several studies as well ${ }^{7}$. On the other hand, there is a little evidence about the benefits of the cognitive stimulation in patients with vNCD.

In recent years some attention has been deserved in devising computer-aided programs to activate cognitive functioning in patient with Mild Cognitive Impairment (MCl) or dementia.

A review and meta-analysis ${ }^{8}$ report data of 12 computer-based cognitive intervention studies in patients with dementia, showing intermediate results regarding cognition and anxiety and small impacts concerning depression. From the other hand, no effect was observed on functioning in daily activities.

Similar intermediate results emerge from four RCTs on cognitive training ${ }^{9}$, since half of the studies did not produce significant outcomes; only one study reported benefits on episodic memory and abstract reasoning, while the remaining study highlighted that computer-based cognitive interventions can slow down cognitive decline.

Finally, a recent systematic review ${ }^{10}$ highlights that several factors may account for the discrepancies reported across the studies carried on by computer-aided programs, i.e., the type and size of populations, the etiology of cognitive impairment etc. In particular, the Authors point to the different levels of cognitive impairment, suggesting that different stages of the dementia pathway are associated with preferred stimulation activities. People with mild or moderate dementia tend to prefer challenging tasks, such as the ones provided via videogames modality.

According to suggestions of the literature, aim of the present study was to evaluate the efficacy on cognitive measures, behavioral and depressive symptoms in a group of patients suffering from mild to moderate vNCD by means of computer-aided cognitive training program.

\section{METHODS}

\section{DESIGN AND SUBJECTS}

The retrospective study included 55 patients with major vNCD according to DSM-5 criteria $^{2}$ divided into two distinct subgroups, namely, the treatment (TG) and control group (CG). The TG consisted of 20 men and 11 women with a mean age of $73.3(\mathrm{SD}=9.5)$ and a mean education (years of schooling) of $8.0(S D=3.2)$. The CG had a mean age of $72.2(\mathrm{SD}=9.3)$ and a mean education of $8.3(S D=3.4)$. Both age and education did not significantly differed (Mann-Whitney $U$ test) between TG and CG (Age: $U=342.0$; $p$ ns; Education: 352.5; $p$ ns). All subjects of the TG were outpatients recruited by convenience as referred to the rehabilitative ward of the "Villa delle Magnolie" Clinic in Castelmorrone (Campania, Italy), whereas CG subjects were outpatients followed by the Memory Clinic of the CTO Hospital in Naples (Campania, Italy). All patients lived at home with their spouse and/or relatives. The CG subjects were matched with TG patients according to better concordance in terms of age, sex, education and grading of cognitive impairment.

Inclusion criteria for both groups were, along with clinical diagnosis of vNCD, an age from 55 to 85 years; at least five years of formal education. Exclusion criteria included previous history of Epilepsy, Parkinson's disease, major psychiatric disorders, alcohol or substance abuse, drugs interfering with cognition, relevant medical conditions not controlled by treatment.

All patients completed a clinical protocol including medical history, standard neurological examination, screening cognitive testing and blood chemistry.

All but two subjects from both groups underwent at least one brain MRI without gadolinium. In all cases a Fazekas score equal to or greater than 2 was recorded. Two subjects underwent brain CT scan because of the presence of a hearth pace-maker, both showing the picture of a relevant leukoariosis. Most of patients suffered from cardiovascular (hypertension, chronic ischemic cardiopathy, etc.) or metabolic disease (i.e, diabetes), but a precise cumulative impact of the diseases (i.e. CIRS) has not been calculated.

\section{Procedures}

Patients from both groups were evaluated at baseline (TO) and at endpoint at 24 weeks (T1) in order to asses: 1) general cognition by means of the Mini Mental State Examination (MMSE) ${ }^{11,12 ;}$ 2) depressive symptoms by the Montgomery and Aasberg depression rating scale ${ }^{13}$; 3) neurobehavioral symptoms by means of the Neuropsychiatric Inventory for psychopathology (NPI-P) ${ }^{14}$. All assessment tools were administered by certified Psychologists. Furthermore, care was given in selecting the examiner, since each evaluation was performed by a Psychologist different from that of the previous one. These investigators were blinded to the patient's group. Patients belongings to the TG underwent a 24 weeks of computer-aided treatment by the Neurotablet ${ }^{\circledR}$, three sessions per week of about 50-60 min duration. The Neurotablet ${ }^{\circledR}$ training encompasses a set of different exercises tapping the main cognitive domains, namely Attention, Memory, Language, Perception and Executive functions. The platform was chosen because of implemented on cheap and easy-to-use hardware and its possibility in customizing and tailoring the program. Cognitive training was guided or supervised by specially trained personnel (motor and speech therapists). 


\section{Statistics}

Given the small sample and the non-continuous characteristics of variables, only non-parametric tests have been applied. The difference between $T G$ and $C G$ groups at T0 and T1 has been checked by the Mann Whitney $U$ test. The within comparison between TO and $\mathrm{T} 1$ has been performed by means of the Wilcoxon signed rank test. Significance level has been set at $p$ 0.05 level, one-sided.

\section{RESULTS}

The sample size calculation at 95\% confidence level (5\% margin of error; $p$.05) gave a minimum sample size of 49 subjects.

Table 1 reports means, SD and comparison (Mann-Whitney) of MMSE, MADRS and NPI-P of the two groups at TO and T1. Non difference approached significance on each measure at TO. Conversely, a significant difference was observed at T1; TG's MMSE scores increased of more than one point, whereas in CG a decrease of almost 2.5 points was observed. A difference on measures of behavioral disorders was also observed. No difference approached significance between groups on the MADRS scores.

As regards within group analysis, TG showed significant increase of MMSE at pre-post comparison $(Z=-4.457$; $p<0.0001)$ and decrease of both MADRS $(Z=-4.356$;
$\mathrm{P}<0.0001)$ and NPI-P $(Z=-4.121 ; p<0.0001)$ scores. $A$ reverse effect on MMSE scores was observed in $C G$ patients, who showed a significant decrease of MMSE scores $(Z=-4.107 ; p<0.0001)$, with no significant change on depression (MADRS) and behavioral disorders (NPI-P) (See Figure 1).

No participants experienced hospital admissions over the observation period.

\section{DISCUSSION}

The present study evaluated the efficacy of a 24 weeks computerized cognitive training on cognitive measures, behavioral and depressive symptoms in patients suffering from vNCD by comparing a TG to a CG. While the effect of rehabilitation treatments is widely studied in patients suffering from $A D{ }^{15}$, stroke ${ }^{7}$ and traumatic brain injuries ${ }^{16}$, only few studies have been focused on patients with VNCD.

The treated VNCD group showed significant better cognitive performances after the treatment, while the CG exhibited decreased scores at T1 after a similar period of observation. These results suggest that benefits of computerized cognitive training on natural cognitive deterioration process may be observed in patients suffering from vNCD. The TG group showed as well a reduction of behavioral disturbances after the treatment. Multiple factors probably influenced the outcome. It is

Table I. (A,B).

A. Number of participants, age, education and functional status (IADL, splitted by sex) of the two subgroups; B. Mean, median [Md], standard deviation (SD) and comparison between groups (BG) and within groups (WG) of patients with treated (TG) and untreated (CG) Vascular cognitive impairment on the MMSE, MADRS and NPI-P at baseline (T0) and at endpoint (T1).

\begin{tabular}{|c|c|c|c|}
\hline \multicolumn{4}{|l|}{ A } \\
\hline & & TG (Mean, Md, SD) & CG (Mean, Md, SD) \\
\hline \multicolumn{2}{|l|}{ Participants } & $31(\mathrm{M}=20 ; \mathrm{F}=11)$ & $24(M=16 ; F=8)$ \\
\hline \multicolumn{2}{|l|}{ Age } & $73.3[74.0](9.5)$ & 72.2 [74.0] (9.4) \\
\hline \multicolumn{2}{|l|}{ Education } & $8.0[8.0](3.2)$ & 8.3 [8.0] (3.3) \\
\hline \multirow[t]{2}{*}{ IADL } & $\mathbf{M}$ & $3.1[3.0](1.1)$ & $3.0[3.0](1.1)$ \\
\hline & $\mathbf{F}$ & $4.6[5.0](1.6)$ & $4.9[5.0](1.2)$ \\
\hline
\end{tabular}

\begin{tabular}{|c|c|c|c|c|c|c|}
\hline \multicolumn{7}{|l|}{ B } \\
\hline \multirow[b]{2}{*}{ Tool } & \multirow[b]{2}{*}{ Group } & \multicolumn{2}{|c|}{ TO } & \multicolumn{2}{|c|}{ T1 } & \multirow[b]{2}{*}{$\begin{array}{c}\text { WG } \\
\text { Mann-Whitney }\end{array}$} \\
\hline & & $\begin{array}{c}\text { Score } \\
\text { Mean, Md, SD }\end{array}$ & $\begin{array}{c}\text { BG } \\
\text { Mann-Whitney }\end{array}$ & $\begin{array}{c}\text { Score } \\
\text { Mean, Md, SD }\end{array}$ & $\begin{array}{c}\text { BG } \\
\text { Mann-Whitney }\end{array}$ & \\
\hline \multirow[t]{2}{*}{ MMSE } & TG & $18.0[18.0](4.6)$ & $\mathrm{U}=347.0(\mathrm{NS})$ & $19.2[19.0](4.3)$ & $U=238.5(p 0.02)$ & $Z=-4.457(p<0.0001)$ \\
\hline & CG & $18.5[18.5](4.7)$ & & $16.1[16.5](5.3)$ & & $Z=-4.107(p<0.0001)$ \\
\hline \multirow[t]{2}{*}{ MADRS } & TG & 13.1 [12.0] (4.2) & $\mathrm{U}=371.5(\mathrm{NS})$ & $11.0[10.0](3.1)$ & $\mathrm{U}=273.0(\mathrm{NS})$ & $Z=-4.356(p<0.0001)$ \\
\hline & CG & $13.2[12.5](4.4)$ & & $13.3[13.0](4.7)$ & & p NS \\
\hline \multirow[t]{2}{*}{ NPI-P } & TG & $9.2[9.0](3.4)$ & $\mathrm{U}=346.0$ (NS) & $7.5[7.0](4.4)$ & $U=252.0(p<0.05)$ & $Z=-4.121(p<0.0001)$ \\
\hline & CG & $8.8[8.5](3.8)$ & & $9.3[9.0](3.4)$ & & $\mathrm{pNS}$ \\
\hline
\end{tabular}




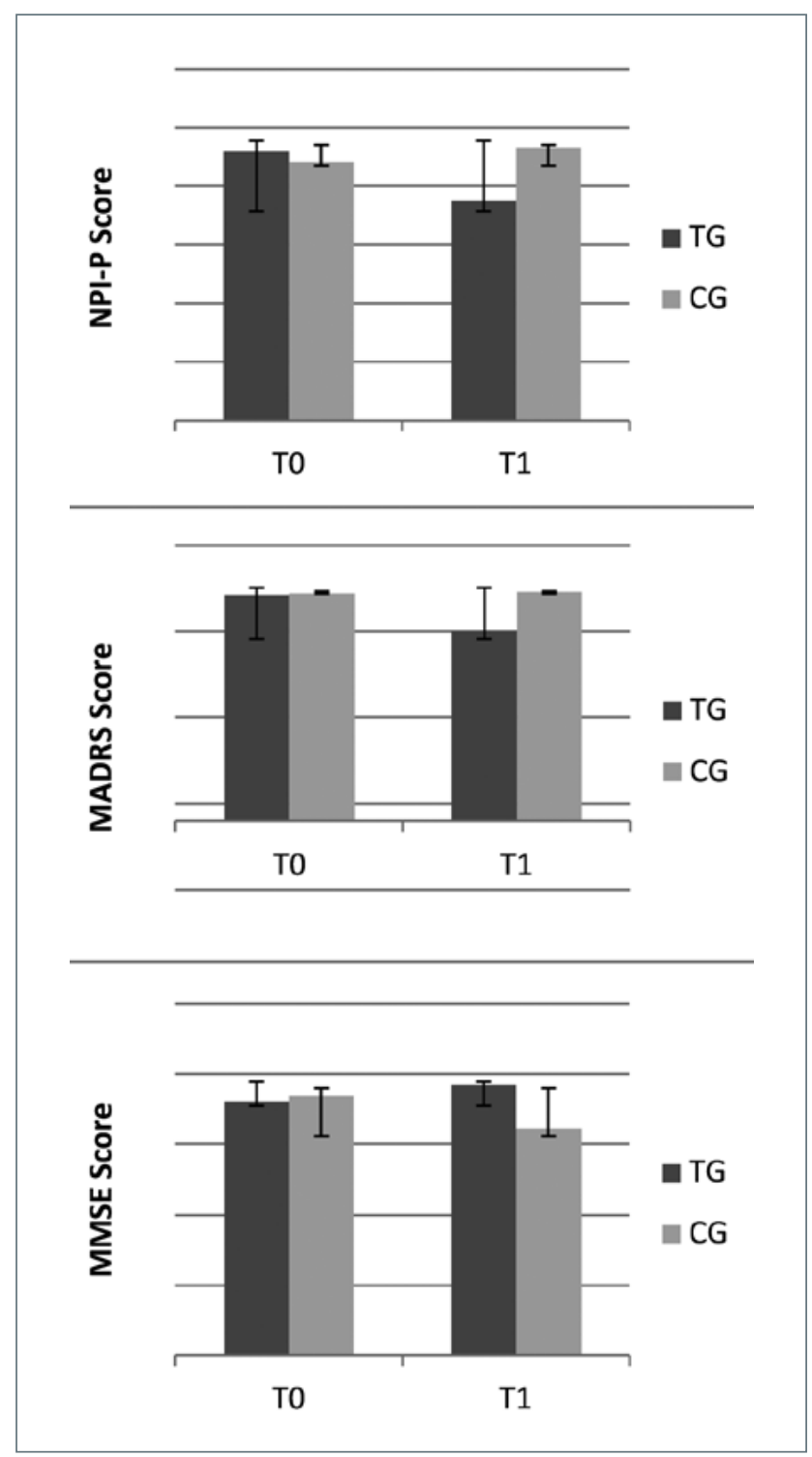

Figure 1. Comparison between treatment group (TG) and control group (CG) at baseline (dark grey) and at 24 weeks (light grey). Error bar indicates standard error.

conceivable that the reduction of behavioral disorders improved the relationship with the caregivers, facilitated the taking of therapy for the vascular risk factors and reduced the intake of cognitively interfering drugs. This could result in better cognitive performances compared to those of the control group.

According to previous contributions on non-pharmacological treatments in patients suffering from $A D$, persons with vNCD can benefit from cognitive intervention in both cognitive and behavioral domains.

The present study is not free from several limitations, namely, the small size and type of the group under investigation, along with the lacking of a more careful evaluation of the several conditions, other than neurological, potentially influencing cognitive functioning. Beside this, we believe that another putative bias could be ascribed to the difficulty in carefully matching groups according to the site and extension of the vascular lesions. Further studies will better take into account these features.

\section{CONCLUSIONS}

Since several contributions demonstrated the effectiveness of non-pharmacological intervention in patient with dementia, stroke or traumatic brain injuries, a lack of evidence is currently available about the usefulness of cognitive training in people with VNCD. The present study showed the positive effects of a computerized cognitive training on persons suffering from chronic vNCD by comparing the cognitive, behavioral and mood domains of a "treatment group" with a "control group". Positive effects were recorded on both cognition and behavior, but not on mood domain. As the evidence of several contribution indicates the importance of cognitive simulation for dementia, the present study would underline the importance of providing non-pharmacological intervention in vNCD as well.

\section{Ethical consideration}

All patients gave their informed consent to the study, which was carried on according to the Declaration of Helsinki. The present contribution is a retrospective study and ethics approval is not necessary as declared by The National Code on Clinical Trials.

\section{Acknowledgement}

None.

\section{Conflict of interest}

On behalf of all Authors, the corresponding author states that there is no conflict of interest.

\section{Funding}

This research did not receive any specific grant from funding agencies in the public, commercial, or not-forprofit sectors.

\section{References}

1 Gorelick PB, Scuteri A, Black SE, et al.; American Heart Association Stroke Council, Council on Epidemiology and Prevention, Council on Cardiovascular Nursing, Council on Cardiovascular Radiology and Intervention, and Council on Cardiovascular Surgery and Anesthesia. Vascular contributions to cognitive impairment and dementia: a statement for healthcare professionals from the american heart association/american stroke association. Stroke 2011;42:26722713. https://doi.org/10.1161/STR.0b013e3182299496 
2 American Psychiatric Association. Diagnostic and statistical manual of mental disorders. $5^{\text {th }}$ ed. Washington, DC: Publisher 2013.

3 Woods B, Aguirre E, Spector AE, et al. Cognitive stimulation to improve cognitive functioning in people with dementia. Cochrane Database System Rev 2012:CD005562. https://doi.org/10.1002/14651858.CD005562.pub2.

4 Lök N, Bademli K, Selçuk-Tosun A. The effect of reminiscence therapy on cognitive functions, depression, and quality of life in Alzheimer patients: randomized controlled trial. Geriatric Psych 2018;34:47-55. https://doi. org/10.1002/gps.4980

5 Spector A, Davies S, Woods B, et al. Reality orientation for dementia: a systematic review of the evidence for its effectiveness. Gerontologist 2000;40:206-212. https://doi. org/10.1093/geront/40.2.206

6 Aguirre A, Woods R, Spector A, et al. Cognitive stimulation for dementia: a systematic review of the evidence of effectiveness from randomised controlled trials. Ageing Res Rev 2013;12:253-262. https://doi.org/10.1016/j. arr.2012.07.001

7 Sarfo FS, Ulasavets U, Opare-Sem OK, et al. Tele-rehabilitation after stroke: an updated systematic review of the literature. JStroke Cerebrovasc Dis 2018;27:2306-2318. https:// doi.org/10.1016/j.jstrokecerebrovasdis.2018.05.013

8 García-Casal JA, Franco-Martín M, Perea-Bartolomé MV, et al. Electronic devices for cognitive impairment screening: a systematic literature review. Int J Technol Assess Health Care 2017;33:654-673. https://doi.org/10.1017/ S0266462317000800
9 Klimova B, Maresova P. Computer-based training programs for older people with mild cognitive impairment and/ or dementia. Front Hum Neurosci 2017;11:262. https:// doi.org/10.3389/fnhum.2017.00262

10 Pappadà A, Chattat R, Chirico I, et al. Assistive technologies in dementia care: an updated analysis of the literature. Front Psychol 2021;12:644587. https://doi.org/10.3389/ fpsyg.2021.644587

11 Folstein MF, Folstein SE, McHugh PR. "Mini-mental state". A practical method for grading the cognitive state of patients for the clinician. J Psychiatr Res 1975;12:18998. https://doi.org/10.1016/0022-3956(75)90026-6

12 Carpinelli Mazzi M, lavarone A, Russo G, et al. Mini-mental state examination: new normative values on subjects in Southern Italy. Aging Clin Exp Res 2020;32:699-702. https://doi.org/10.1007/s40520-019-01250-2

13 Montgomery SM. Depressive symptoms in acute schizophrenia. Prog Neuropsychopharmacol 1979;3:429-433. https://doi.org/10.1016/0364-7722(79)90058-4

14 Cummings JL, Mega M, Gray K, et al. The Neuropsychiatric Inventory: comprehensive assessment of psychopathology in dementia. Neurology 1994;44:2308-2314. https:// doi.org/10.1212/wnl.44.12.2308

15 Choi J, Twamley EW. Cognitive rehabilitation therapies for Alzheimer's disease: a review of methods to improve treatment engagement and self-efficacy. Neuropsychol Rev 2013;23:48-62. https://doi.org/10.1007/ s11065-013-9227-4

16 Alashram AR, Annino G, Padua E, et al. Cognitive rehabilitation post traumatic brain injury: a systematic review for emerging use of virtual reality technology. J Clin Neurosci 2019;66:209-219. https://doi.org/10.1016/j. jocn.2019.04.026 
Table III. Rank regression between vulnerability and related factors among the elderly in Khuzestan province.

\begin{tabular}{|c|c|c|c|c|c|}
\hline \multicolumn{2}{|l|}{ Independent variables } & \multicolumn{2}{|c|}{ Adjusted model } & \multicolumn{2}{|c|}{ CI 95\% } \\
\hline & & \multirow{2}{*}{\begin{tabular}{|l} 
OR \\
0.712
\end{tabular}} & \multirow{2}{*}{$\begin{array}{l}\text { Sig. } \\
.003\end{array}$} & \multirow{2}{*}{$\begin{array}{c}\text { Lower } \\
0.570\end{array}$} & \multirow{2}{*}{$\begin{array}{l}\text { Upper } \\
0.891\end{array}$} \\
\hline \multirow[t]{2}{*}{ Gender } & Male & & & & \\
\hline & (Female R) & & & & \\
\hline \multirow[t]{3}{*}{ Age group } & $60-74$ & 0.183 & .000 & 0.124 & 0.269 \\
\hline & $75-85$ & 0.411 & .000 & 0.278 & 0.608 \\
\hline & (86 and above $\mathrm{R}$ ) & & & & \\
\hline \multirow[t]{2}{*}{ Marital status } & Single & 1.262 & .055 & 0.995 & 1.602 \\
\hline & (Married R) & & & & \\
\hline \multirow[t]{4}{*}{ Arrangements of life } & Alone & 1.330 & .243 & 0.824 & 2.146 \\
\hline & Only with spouse & 1.304 & .083 & 0.966 & 1.759 \\
\hline & With spouse and children & 1.084 & .554 & 0.830 & 1.415 \\
\hline & (Only with children R) & & & & \\
\hline \multirow{6}{*}{ Level of education } & Illiterate & 0.978 & .925 & 0.619 & 1.545 \\
\hline & Elementary & 0.874 & .510 & 0.585 & 1.305 \\
\hline & Middle school & 1.063 & .742 & 0.739 & 1.529 \\
\hline & High school & 1.156 & .412 & 0.818 & 1.634 \\
\hline & High school degree & 0.866 & .407 & 0.617 & 1.216 \\
\hline & (University R) & & & & \\
\hline \multirow{6}{*}{$\begin{array}{l}\text { Household head's income } \\
\text { (Toman) }\end{array}$} & Less than 1 million & 1.200 & .394 & 0.789 & 1.826 \\
\hline & 1 to 1.5 million & 1.400 & .101 & 0.936 & 2.094 \\
\hline & 1.5 to 2 million & 1.369 & .098 & 0.944 & 1.985 \\
\hline & 2 to 2.5 million & 0.886 & .541 & 0.600 & 1.307 \\
\hline & 2.5 to 3 million & 1.150 & .500 & 0.766 & 1.728 \\
\hline & (More than 3 million R) & & & & \\
\hline \multirow[t]{3}{*}{ Number of drugs taken } & No & 0.749 & .141 & 0.509 & 1.101 \\
\hline & $1-5$ & 0.741 & .012 & 0.587 & 0.935 \\
\hline & (More than 5 drugs R) & & & & \\
\hline \multirow[t]{2}{*}{ Hospital history } & Yes & 1.416 & .006 & 1.106 & 1.814 \\
\hline & (No R) & & & & \\
\hline \multirow{2}{*}{$\begin{array}{l}\text { Physical activity } \\
\text { per week }\end{array}$} & Less than 150 minutes & 1.125 & .371 & 0.869 & 1.457 \\
\hline & (More than 150 minutes R) & & & & \\
\hline \multirow[t]{2}{*}{ Malnutrition } & Yes & 1.244 & .057 & 0.994 & 1.558 \\
\hline & (No R) & & & & \\
\hline \multirow[t]{2}{*}{ Social participation } & (No) & 1.242 & .061 & 0.990 & 1.557 \\
\hline & (Yes R) & & & & \\
\hline \multirow[t]{2}{*}{ Life events } & No & 1.062 & .590 & 0.854 & 1.319 \\
\hline & (Yes R) & & & & \\
\hline \multirow[t]{2}{*}{ Smoking } & Yes & 0.900 & .396 & 0.705 & 1.148 \\
\hline & (No R) & & & & \\
\hline \multirow[t]{2}{*}{ Interest in the living environment } & No & 1.013 & .916 & 0.797 & 1.287 \\
\hline & (Yes R) & & & & \\
\hline \multirow[t]{2}{*}{ Depression } & No & 0.409 & .000 & 0.324 & 0.515 \\
\hline & (Yes R) & & & & \\
\hline Social support & 0.948 & 0.000 & 0.925 & 0.972 & \\
\hline Pseudo R2 (\%) (final model) & 45.9 & & & & \\
\hline \multicolumn{2}{|c|}{ Goodness of fit tests of the model (final model) } & $\begin{array}{l}\text { Model fit ( } \mathrm{x} \\
\text { Deviance ( } \mathrm{x}\end{array}$ & $\begin{array}{l}1.926 \mathrm{Si} \\
3.317 \mathrm{~d}\end{array}$ & $\begin{array}{l}.001) \\
550 \mathrm{Sig}=\end{array}$ & \\
\hline
\end{tabular}

